\title{
Involving Parents in Paired Reading with Preschoolers: Results from a
}

\section{Randomized Controlled Trial}

Shui-fong Lam ${ }^{\mathrm{a}}$, Kamfung Chow-Yeung ${ }^{\mathrm{b}}$, Bernard P. H. Wong ${ }^{\mathrm{a}}$, Kwok Kiu Lau ${ }^{\mathrm{b}}$, Shuk In Tse ${ }^{\mathrm{b}}$

${ }^{a}$ Department of Psychology, The University of Hong Kong, Pokfulam Road, Hong Kong, China

${ }^{\mathrm{b}}$ Hong Kong Young Women’s Christian Association, 1, MacDonnell Road, Hong Kong, China

Correspondence concerning this paper should be addressed to Shui-fong Lam, Department of Psychology, University of Hong Kong, Pokfulam Road, Hong Kong, China. E-mail: lamsf@hku.hk. Telephone: (852) 2859-2388. Fax: (852) 2858-3518. 


\title{
Involving Parents in Paired Reading with Preschoolers: Results from a Randomized Controlled Trial
}

\begin{abstract}
A paired reading program was implemented for 195 Hong Kong preschoolers (mean age $=4.7$ years) and their parents from families with a wide range of family income. The preschoolers were randomly assigned to experimental or waitlist control groups. The parents in the experimental group received 12 sessions of school-based training on paired reading in seven weeks. They were required to do paired reading with their children for at least four times in each of these seven weeks. At the end of the program, the preschoolers in the experimental group had better performance in word recognition and reading fluency than their counterparts in the control group. They were also reported as more competent and motivated in reading by their parents. More importantly, the program had many favorable effects on parents. Parents in the experimental group had higher self-efficacy in helping their children to be better readers and learners. They also reported that they had better relationships with their children. Their changes in relationships and self-efficacy were found to mediate the program impact on some of the child outcomes. However, family income did not moderate the effectiveness of the program. Families with high and low income both benefited from the program alike.
\end{abstract}

Keywords: paired reading, parental involvement, preschoolers, family income, parenting 


\section{Involving Parents in Paired Reading with Preschoolers: Results from a \\ Randomized Controlled Trial}

\section{Introduction}

An extensive literature suggests that parental involvement in reading is beneficial to children (e.g., Bus, van Ijzendoorn, \& Pellegrini, 1995; Erion, 2006; Mol, Bus, De Jong, \& Smeets, 2008; Sénéchal \& Young, 2008). Some studies even showed increased parental involvement to be more effective in increasing children's performance than reading instruction at school by teachers or specialists (Hewison, 1988; Lonigan \& Whitehurst, 1998; Tizard, Schofield, \& Hewison, 1982). There are many advantages of family-based interventions over school-based interventions. Most family-based interventions take place in a one-on-one context rather than in small group settings. They provide ample opportunity for probing, practice, teaching, feedback, and repetition in the learning process (Lonigan \& Whitehurst, 1998). In addition, as family-based interventions involve permanent and positive changes in the parenting skills and routines of family life, they can promote literacy skills for the long term (van Steensel, McElvany, Kurvers, \& Herppich, 2011). In addition, parental involvement plays a critical role in the nurturance of children's motivation in learning. It enhances a sense of relatedness between parents and children, and helps children to internalize the importance of education (Gonzalez-DeHass, Willems, \& Doan Holbein, 2005).

\subsection{Barriers for parental involvement}

Although it is widely accepted that parental involvement in academic performance is important, not all parents are ready to participate in their children's literacy development. Weinberger (1996) found that only a small proportion of the parents in her study felt that they knew how reading was taught in school. McMackin 
(1993) also pointed out that many parents feel inhibited about teaching their children to read once formal reading instruction begins in school. Even when parents are willing and eager to read with their children at home, they are unlikely to initiate a regular reading program with their children unless school makes a special effort to involve them (Epstein, 1987).

Baker (2003) warned that teachers should not assume parents know how to help their children in reading. She advised that "teachers should provide specific advice on what to read, how much to read, how long to read, how to respond to mistakes, what kind of discussions to hold with children, and how to keep the experience enjoyable” (p. 93). Her advice is particularly important for working with low-income families. Parental involvement is a form of social capital (Coleman, 1988, 1992). Families with different socio-economic status (SES) may not have equal access to this social capital. Low-income parents do not have the same paid leave and flexibility to attend to the educational needs of their children as higher-income parents (Heymann \& Earle, 2000). Consequently, they engage less in school-related activities with their children than do parents with high SES (Evans, 2004). When it comes to their perspective on reading, parents of different SES are also different. Past studies have shown that parents with low income and less education tended to focus on drilling of reading skills but parents with higher income and more education tended to focus on informal and playful opportunities for literacy learning (Fitzgerald, Spiegel, \& Cunningham, 1991; Goldenberg, Reese, \& Gallimore, 1992; Weigel, Martin, \& Bennett, 2006). These different focuses may result in different parental practices and child outcomes. Sonnenschein and her colleagues (1997) found that parents with an entertainment orientation (vs. a skills orientation) tended to read more to their children and reported using a more sensitive manner of interaction. In addition, a substantial amount of 
research on the relation between familial SES and children's academic achievement has indicated that children of parents with higher SES had better academic performance than children of parents with lower SES (e.g., Ginsburg \& Bronstein, 1993; Marjoribanks, 1996; Scarborough \& Dobrich, 1994; White, 1982; White, Reynolds, Thomas, \& Gitzlaff, 1993).

In view of the above findings, many educators (e.g., Chang, Park, Singh, \& Sung, 2009; Tizard et al., 1982) advocate that actual guidance and support should be provided to parents with low SES so that they can contribute to their children's academic success. Parents need more specific strategies to be effective in reading with their children at home. Kelly-Vance and Schreck (2002) suggested that schools can be an important catalyst in training parents in reading instruction.

The present paper reports a parental involvement program in which schools made a substantial effort to provide guidance and support to parents so that they could help their preschoolers to read at home. The parents came from families with a wide range of income levels. The tutoring strategies adopted were based on the paired reading program invented by Morgan (1976) and further developed by Topping (1987).

\subsection{Paired reading program}

Paired reading strategies were adopted because they are easy to acquire and carry out. They are cost-effective and time-efficient methods for teaching children to read. As they are neither difficult nor costly, they can be readily mastered and implemented by parents with low income and less education. In a paired reading program, parents and children read together at home for five to fifteen minutes, five days a week, on the “little and often principle” (Topping, 1986). The procedure is relatively simple and easy to manage: 
The procedure consists of two phases: simultaneous and independent reading. The child is allowed to choose any book and the child and parent begin reading out loud together in close synchrony (simultaneous reading). When the child makes a mistake, the parent supplies the correct word, the child repeats it, and they continue reading. When the child feels confident enough to read alone, s/he gives the parent a signal and the parent stops reading (independent reading). If the child makes a mistake, the parent provides the correct word, the child repeats it, and the pair begin reading again. (Law \& Kratochwill, 1993, p. 120)

This procedure gets children some peaceful private attention from their parents. In addition, the procedure gives parents a clear, straightforward, and enjoyable way of helping their children. Therefore, parents should not "get confused, worried, or bad tempered about reading” (Topping, 1987, p. 611). In fact, research findings have demonstrated the effectiveness of paired reading. The Kirless Paired Reading Project was the largest of its kind in the United Kingdom $(\mathrm{N}=1,165)$. The results of this project showed that children on average improved their reading at a rate of 3.7 times "normal" gains in reading accuracy and 4.8 times "normal" gains in reading comprehension. Parents also reported that their children were reading more, understanding books better, and more willing to read (Topping, 1986).

Despite these positive research findings, paired reading programs still invite criticism from some researchers. From a motivational standpoint, Baker (2003) criticized it for not giving systematic attention to getting meaning from the reading materials. She argued that the affective atmosphere of shared reading is more positive when parents and children discuss the story content rather than focus on accurate word reading. In a review of the research on emergent literacy in early childhood, 
Whitehust and Lonigan (1998) concluded that adult-child verbal interactions were important in the acquisition of literacy skills. For example, DeTemple (2001) found that the chat that goes beyond the reading of the story can promote the development of a cluster of language skills that children will be expected to use in school. The abundance of evidence pointing to the importance of parent-child talk has led Tabos, Snow, and Dickinson (2001) to posit that how parents read with their children is as crucial as whether and how often parents and children read together. They suggested that the inclusion of enriched conversation during book reading is of great value.

In view of the importance of parent-child discussion, Overett and Donald (1998) added a new dimension to Topping's model of paired reading. They emphasized the discussion and interaction between parents with children around the story, title, and illustrations. They thought that it is important for the parent-child dyad to actively discuss and think about meaning before, during, and after reading. Therefore, the paired reading procedure should also include

reciprocal questioning around the reading materials; prediction with regard to the story line and vocabulary; relating the reading materials to the child's present experience and knowledge, assisting insights into less explicit levels of meaning; and using contextual clues in thinking about the understanding the reading matter. (Overett \& Donald, 1998, p. 350)

The present study modified Topping’s (1987) paired reading approach according to the suggestions of Overett and Donald (1988). The discussion for the construction of meaning was added to the procedure. To enrich the discussion, some techniques of dialogic reading (Whitehurst et al., 1988) were adopted. Compared to paired reading, dialogic reading is less structured in procedure but more elaborate in the techniques in interactive discussion. In the present study, the specific use of purposeful questioning 
(How? What? Where? When? Why? Who?) was modeled and practiced by the parents.

\section{Overview of the study}

The present study was a collaboration between school personnel and university researchers. With the commitment of parental involvement, a group of principals and teachers in Hong Kong launched a paired reading program in their preschools that served families with a wide range of family income. To evaluate the effectiveness of the program, they invited researchers from the university to conduct a randomized controlled trial.

Most of the past studies on paired reading did not focus on preschoolers. Its effectiveness with preschoolers, particularly Chinese preschoolers, is yet to be ascertained. The Chinese written language is difficult to learn because its written system is logographic instead of alphabetic (Barnitz, 1982). Each Chinese character maps onto a spoken syllable. Learning to read, Chinese children need to remember links between syllables and characters. A character-recognition vocabulary of 3,000 is required for understanding a newspaper (Jiang \& Li, 1985). The relatively complicated nature of Chinese orthography may make learning to read difficult. Nevertheless, children in Hong Kong start reading early. As shown in the results of a questionnaire survey (Li \& Rao, 2005), most teachers in Hong Kong (98.4\%) reported that they provided instruction in reading Chinese to children under five years of age. According to McBride-Chang et al. (2008), Hong Kong Chinese children can master approximately 200 Chinese characters by the end of kindergarten, and they typically begin training in reading from the second semester of their first year in kindergarten (at roughly 3.5 years of age). The accounts given by the above researchers are consistent with the list of developmental milestones provided by the Education 
Bureau (2006) to preschool educators in Hong Kong. The list specifies that preschoolers of four or five years old are expected to understand the layout of the Chinese texts, be able to recognize some familiar words, and read in the company of an adult.

The complexities of written Chinese may make parental involvement more important for learning reading in Chinese language than in alphabetic languages with a less complicated orthography, such as English (Li \& Rao, 2000). The "look and say” approach used to teach Chinese children reading requires children to learn characters one by one through repeated association between form, sound, and meaning (Hanley, Tzeng, \& Huang, 1999). As Lau and McBride (2005) commented, the additional literacy opportunities at home might promote learning of additional characters. However, there is a lack of randomized controlled trials on the effects of parental involvement in Chinese preschoolers' literacy development. The study by Chow and McBride-Chang (2003) is a rare exception in this respect. Nevertheless, it did not focus on paired reading and was not concerned about its impact on parents. As Scher (1998) pointed out, parental involvement is important for a program to strengthen the skills of parents to subsequently improve their children's language and emerging literacy skills. There is a need to investigate not only the effectiveness of a paired reading program with regards to the children but also the impact it has on the parents. It is important to examine if any changes in parents bring along changes in children. In addition, there is a need to investigate whether early parental involvement in literacy development is particularly helpful to families with low income.

The present study has four objectives. The first is to investigate whether the program has a positive impact on Chinese children; the second whether the program has a positive impact on their parents; the third whether program effects on children 
are mediated by the changes in parents; and the fourth whether the program is more helpful to families with low income than those with high income. Four sets of hypotheses were formulated for children, parents, mediation effect, and family income, respectively.

\subsection{Children}

With random assignment of the preschooler participants to the experimental and control conditions, there should not be a significant difference between reading performance and motivation at the beginning of the program. Given that all the preschoolers are exposed to normal school learning for the duration of the paired reading program, it is expected that the preschoolers in both conditions have better reading performance and motivation after the paired reading program. However, if the paired reading program is effective, the rate of improvement for the preschoolers in the experimental condition should be higher than for their counterparts in the control condition. Therefore, at the end of the paired reading program, the preschoolers in the experimental condition are expected to have better reading performance and motivation than the preschoolers in the control condition.

\subsection{Parenting}

As parents are the tutors of their children and they are taught how to use the paired reading strategies, the paired reading program does not only have an impact on children but also on parents. Most family-based interventions aim to make positive changes in the routines of family life (van Steensel et al., 2011). The present program is no exception. Because of random assignment, there is no difference between the experimental and control conditions at the beginning of the program. It is expected that at the end of the program the parents who have received support in the experimental condition have higher self-efficacy in helping their children to read and 
to learn than their counterparts in the control condition. They are also expected to report a better relationship with their children than the parents in the control condition. Unlike children, parents are grown-ups whose attitudes and behaviors are relatively stable if there is no effective intervention. Therefore, it is expected that an improvement in self-efficacy and parent-child relationship is only evident in the experimental condition but not the control condition. This pattern is slightly different from that of the children. Over time, children in both conditions grow up and make improvements anyway. The difference lies in the magnitude of improvements.

\subsection{Mediation effects of parental changes}

Scher (1998) argued that strengthening the skills of parents is important to a program because it will subsequently improve their children's language and emerging literacy skills. The changes in parenting skills may be one of the mechanisms by which some programs have positive impact on child outcomes. Therefore, it is possible that the program effect on children is mediated by the changes in parenting. In other words, the impact of the program on children is explained by the changes in parents.

\subsection{Interaction between family income and condition}

In a previous study of a paired reading program (Topping \& Lindsay, 1991), the children in the low SES category yielded bigger gains than the children in the high SES category. This finding is understandable because parents of low income and less education may engage less in school-related activities with their children than do parents with high SES (Evans, 2004). In view of this difference, a paired reading program may be more beneficial to children and parents with low family income because it is a deliberate effort by the school personnel to foster parental involvement by giving actual support and guidance. The less engaged parents before the 
intervention may be the ones who benefit the most. Therefore, it is expected that the program has a greater impact on families with low income than those with high income.

\section{Method}

\subsection{Participants}

The participants were 195 Chinese preschoolers and their parents from 10 preschools operated by the Hong Kong Young Women’s Christian Association. These 10 schools were located in 9 different districts out of a total of 18 districts in Hong Kong. The participating parents had a wide range of family income. Although these schools were not randomly selected from all the preschools in Hong Kong, they were considered to be comparable to most preschools in Hong Kong in terms of demographics. The preschool curriculum in Hong Kong comprises three levels: Level 1 for children aged three years, Level 2 for children aged four years, and Level 3 for children aged five years. All the participants were at Level 2. They were randomly assigned to either the experimental group $(n=101)$ or the waitlist control group $(n=$ 94). As stratified random assignment was adopted, each class had more or less an equal number of preschoolers assigned to the experimental and the control groups. The two groups of preschoolers were taught by the same teachers in their classrooms although the experimental group experienced the paired reading program first and the waitlist control group experienced it later. The two groups of preschoolers were not significantly different in their age $\left(M_{\text {experimental }}=4.70, S D=.34 ; M_{\text {control }}=4.69, S D\right.$ $=.33), t(193)=.07, p=.95$, Cohen's $d=.03$. Neither were they significantly different in the ratio of gender, $\chi^{2}=2.53, d f=1, p=.11$. There were 52 boys in the experimental group and 59 boys in the control group. 
Most of the parents who participated in the paired reading program were mothers. In the experimental group, mothers made up $83 \%$, fathers $11 \%$, grandparents and others $6 \%$. In the control group, mothers made up $90 \%$, fathers $4 \%$, grandparents and others $6 \%$. There was no significant difference in the status of the parents between the two groups, $\chi^{2}=2.70, d f=2, p=.26$. Neither was there a significant difference in the age of the parents between the two groups $\left(M_{\text {experimental }}=36.95, S D=6.40 ; M_{\text {control }}=\right.$ 36.45, $S D=.7 .10), t(193)=.48, p=.63$, Cohen’s $d=.07$.

In the experimental group, the percentages of parents who had a full-time job, a part-time job, and no job were $46 \%, 8 \%$, and $46 \%$, respectively. In the control group, the percentages of the parents who had a full-time job, part-time job, and no job were $50 \%, 13 \%$, and $37 \%$, respectively. There was no significant difference in the employment status of the parents between the two groups, $\chi^{2}=2.32, d f=2, p=.31$. According to their annual family income, the parents were categorized into five groups: 1) on welfare; 2) below HK\$84,000 (US\$10,770); 3) between HK\$84,000 and HK\$122,000 (US\$15,640); 4) between HK\$122,000 and HK\$224,000 (US\$28,700); and 5) above HK\$224,001. In the experimental group, the percentages of the parents in Groups 1, 2, 3, 4, and 5 were 9.9\%, 18.8\%, 13.9\%, 12.9\%, and 44.6\%, respectively. In the control group, the percentages of parents in Groups 1, 2, 3, 4, and 5 were $10.6 \%$, 14.9\%, $21.3 \%, 14.9 \%$, and $38.3 \%$, respectively. There was no significant difference in annual family income between the two conditions, $\chi^{2}=2.61, d f=4, p=.63$. In view of the demographic background, the two conditions were very similar. The fact that they had similar demographics excludes the possibility that the effects of the program, if any, might be due to different backgrounds of the participants instead of the program itself. 


\subsection{Paired reading program}

The paired reading program lasted for seven weeks and each paired reading exercise was about 10 to 15 minutes. Parents who participated in the program made the commitment to pair read with their children at least four times a week, two of which were carried out at school in the presence of the coaching teacher. In each of these on-site exercises, the coaching teacher observed how the parents did the paired reading with their children and discussed ways to make improvements. Other than these 12 individual coaching sessions, there were two small group sessions with an average of 5 to 6 parents who participated in the program in the same preschool. These two sessions were scheduled in the fourth and seventh weeks as interim and final review, respectively.

\subsection{Treatment fidelity}

To ensure that the teachers who served as the coaches mastered the skills in paired reading and coaching, they were given two phases of training. In the first phase, the focus was on the skills of paired reading. Each teacher would complete a paired reading program with a student at her school four times a week over a seven week period. Supervision was given by a school psychologist or her assistants once a week. Feedback was provided based on the paired reading skill checklist of 33 items. These skills included preparing a suitable setting, giving clear instructions, keeping the right pace, raising different types of questions, giving helpful hints, making corrections, giving praise, providing feedback and encouragement, and keeping clear records. Without exception, all the teachers were able to master the skills towards the end of the training period. Then they moved onto the second phase of the training which focused on the skills of coaching parents. They were observed by the trainers at least twice on how they coached and supported the parents in the paired reading program. Feedback was given to the teachers immediately after the supervision sessions. 
To ensure that the parents mastered the skills in paired reading, similar training was provided. This time, it was the teachers who provided the training and there was only a single phase which focused on the skills of paired reading. Twice a week throughout the seven-week program, a teacher observed how a parent-child dyad read and provided feedback according to the same checklist by which teachers were trained. In the last week of the program, almost all parents were able to master at least $80 \%$ of the items in the checklist.

To check whether the parents read with their children at home as they did in school, a record book was provided to each parent to keep a record of the following items: 1) the date and time when paired reading was conducted; 2) the books that had been read; and 3) the feedback given to the children. The teachers would review these record books with the parents in every coaching and feedback session. According to the record books, close to $99 \%$ of the parents had met the basic requirement of reading with their children four times a week over the seven-week period.

\subsection{Procedures}

Invitation letters were sent to all parents $(N=527)$ with children at Level 2 in the 10 preschools at the beginning of a semester. The response rate was about $37 \%$ as 195 parents volunteered to participate in the program. They were randomly assigned to either the experimental condition or the waitlist control condition within each preschool. The program was first implemented to the experimental condition and then to the control condition. Pretest and posttest data were collected from the children and parents in both conditions. In the pretest, both conditions had not been exposed to the program. In the posttest, the experimental group had completed the program whereas the control group was just about to start the program. Data from the children were collected individually by a small group of four senior teachers who had been trained 
to conduct the two reading tests. Contents of the two reading tests were not released to other teachers. Data from the parents were collected with a questionnaire given to them by school.

\subsection{Measures}

\subsubsection{Word recognition}

To measure how many Chinese words the preschoolers could recognize, a test with 100 Chinese words was developed with the assistance of a group of senior teachers in the 10 preschools. They selected the 100 words from the textbooks at all three levels in their preschools. The words were listed in ascending order according to their level of difficulty. Before the program was implemented, preschoolers in both the experimental and control conditions were tested individually by the assigned teachers with these 100 words. Each preschooler was asked to read these words aloud. One point was given for each word that was read accurately. There was no time limit but the test would be discontinued if the preschooler failed to read ten words consecutively. After the program was completed, the preschoolers were tested again with the same word recognition test.

\subsubsection{Reading fluency}

Another list of 100 Chinese words was developed to test reading fluency. It was also developed with the assistance from the senior teachers. The words in this test were easier than those in the word recognition test. They were selected only from the textbooks and story books at Levels 1 and 2 . The test was administered individually to all the preschoolers before and after the program. They were asked to read the words aloud at their own pace. They could skip the words that they did not know. The number of words they could read within one minute indicated their reading fluency. 


\subsubsection{Parent perceived competence}

Parent perceived competence was measured by a scale of three items in the parent questionnaire (e.g., “My child can recognize many words while reading”). The parents were asked to indicate how much they agreed with these items on a Likert scale ranging from 1 (disagree strongly) to 7 (agree strongly). The average of the three item-scores was used to indicate how parents perceived their children's reading competence. A high score indicated high parent perceived competence. The Cronbach's alphas of the three item-scores were .86 and .88 for pretest and posttest, respectively.

\subsubsection{Parent perceived motivation}

Parent perceived motivation was measured by a scale of three items in the parent questionnaire (e.g., "My child is very interested in reading”). The parents were asked to indicate how much they agreed with these items on a Likert scale ranging from 1 (disagree strongly) to 7 (agree strongly). The average of the three item-scores was used to indicate how parents perceived their children's reading motivation. A high score indicated high parent perceived motivation. The Cronbach's alphas of the three item-scores were .77 and .88 for pretest and posttest, respectively.

\subsubsection{Parent-child relationship}

Parent-child relationship was measured by a scale of four items in the parent questionnaire (e.g., "Compared to the past, I enjoy the time I spend with my child more nowadays”). The parents were asked to indicate how much they agreed with these items on a Likert scale ranging from 1 (disagree strongly) to 7 (agree strongly). The average of the four item-scores was used to indicate the quality of the parent-child relationship. A high score indicated a good parent-child relationship. The Cronbach's alphas of the four item-scores were .78 and .84 for pretest and posttest, respectively. 


\subsubsection{Parent specific self-efficacy}

Parent specific self-efficacy was measured by a scale of four items in the parent questionnaire (e.g., "I know how to use questioning to guide my child in reading”). These items were specific to parent self-efficacy in helping their children to be better readers. The parents were asked to indicate how much they agreed with these items on a Likert scale ranging from 1 (disagree strongly) to 7 (agree strongly). The average of the four item-scores was used to indicate their self-efficacy specific to helping their children to be better readers. A high score indicated high parent self-efficacy in this specific area. The Cronbach's alphas of the four item-scores were .88 and .89 for pretest and posttest, respectively.

\subsubsection{Parent general self-efficacy}

Parent general self-efficacy was measured by a scale of four items in the parent questionnaire (e.g., "Because of my guidance, my child is motivated to learn”). Unlike the items in parent specific self-efficacy, these items were not specific to reading. Instead, they were more general about helping children to learn. The parents were asked to indicate how much they agreed with these items on a Likert scale ranging from 1 (disagree strongly) to 7 (agree strongly). The average of the four item-scores was used to indicate their self-efficacy in helping their children to be better learners in general. A high score indicated high general parent self-efficacy. The Cronbach's alphas of the four item-scores were .89 and .91 for pretest and posttest, respectively.

\subsubsection{Family income}

In the student registration form held in the school archive, the parents reported their annual family income by checking one of the five groups as reported in Section 3.1. Group 1 had the lowest income whereas Group 5 had the highest. According to the statistics provided by the Hong Kong government (Census and Statistics 
Department, 2011), the median annual household income in Hong Kong was about HK\$224,000 (US\$28,720). In the current sample, only participants in Group 5 had an annual family income above the median. For the purpose of data analyses related to family income, the participants were further divided into two groups. The participants with an annual family income in Group 5 (above the median) were categorized as high income group whereas the rest (below the median) were categorized as low income group. The high income group constituted $41.5 \%$ of the sample.

\subsection{Statistical analyses}

As the paired readers in this study might be mothers, fathers, or other relatives, there was a possibility that the intervention effectiveness was a function of the status of the paired readers. To check for this possibility, we did a MANOVA on the experimental group with the status of the paired readers as the fixed factor and the different scores between the pre and post measures as dependent variables. The results indicated that none of the dependent variables was significantly different across the status of the paired readers, all $p s>.05$. As the intervention effectiveness was not a function of the status of the paired readers, we combined the data from these paired readers for further analyses. To examine whether the two conditions were different on the measures in pretest and posttest, independent $t$-tests were performed. To examine whether each condition had any changes on the measures between pretest and posttest, paired-sample $t$-tests were performed. To examine whether parental changes mediated the program effects on the child outcomes, a series of mediation analyses were performed. To investigate whether the program had differential effects on participants with different family income levels, the interaction effect between family income and condition was examined with a series of two-way ANCOVA on the posttest measures, with the pretest measures as covariate. 


\section{Results}

\subsection{Child outcomes}

\subsubsection{Word recognition}

The means and standard deviations of all the child outcomes in pretest and posttest across the two conditions are presented in Table 1. As shown in the table, preschoolers in the two conditions were not significantly different in the number of words they recognized in the pretest, $t(192)=1.56, p=.12$, Cohen's $d=.22$. However, the preschoolers in the experimental condition recognized more words than their counterparts in the control condition in the posttest, $t(190)=3.06, p=.003$, Cohen's $d$ $=.44$. Over time, preschoolers in both conditions had made notable progress. All of them scored higher in the posttest than in the pretest; in the experimental condition: $t(97)=11.77, p<.001$, Cohen's $d=.54$; and in the control condition: $t(92)=6.46, p$ $<.001$, Cohen's $d=.32$.

\subsubsection{Reading fluency}

As shown in Table 1, preschoolers of the two conditions were not significantly different in their reading fluency in the pretest, $t(192)=1.58, p=.12$, Cohen's $d=.23$. In the posttest, however, the preschoolers in the experimental condition read more fluently than their counterparts in the control condition, $t(190)=2.12, p=.04$, Cohen's $d=.31$. Over time, both conditions had made improvements. All preschoolers did better in the posttest than in the pretest; in the experimental condition: $t(97)=10.03, p<.001$, Cohen's $d=.49$; and in the control condition: $t(92)=8.27, p$ $<.001$, Cohen's $d=.40$.

\subsubsection{Parent perceived competence}

As shown in Table 1, parents in both conditions did not have different perceptions of their children's reading competence in the pretest, $t(184)=.75, p=.46$, Cohen's $d=.11$. In the posttest, however, parents in the experimental condition 
perceived their children to have higher reading competence than did parents in the control condition, $t(181)=6.16, p<.001$, Cohen's $d=.90$. Over time, parents in both conditions perceived their children to have better reading competence in the posttest than in the pretest; in the experimental condition: $t(94)=9.09, p<.001$, Cohen's $d=$ 1.00; and in the control condition: $t(87)=2.17, p=.03$, Cohen's $d=.19$.

\subsubsection{Parent perceived motivation}

As shown in Table 1, parents in both conditions were not significantly different in their perceptions of their children's reading motivation in the pretest, $t(184)=.83$, $p=.41$, Cohen's $d=.13$. However, compared to the parents in the control condition, the parents in the experimental condition perceived their children to have higher motivation in the posttest, $t(181)=3.71, p<.001$, Cohen's $d=.54$. Over time, parents in both conditions perceived their children to have higher motivation in the posttest than in the pretest; in the experimental condition: $t(94)=6.73, p<.001$, Cohen's $d$ $=.70$; and in the control condition: $t(87)=2.21, p=.03$, Cohen's $d=.20$.

\subsection{Parenting}

\subsubsection{Parent-child relationship}

The means and standard deviations of all the parenting measures in pretest and posttest across the two conditions are presented in Table 2. As shown in this table, parents in both conditions were not significantly different in their report of their relationship with their children in the pretest, $t(166)=.05, p=.83$, Cohen's $d=.01$. In the posttest, however, the parents in the experimental condition reported a better parent-child relationship than the parents in the control condition in the posttest, $t(162)$ $=2.26, p<.001$, Cohen's $d=.34$. Their scores were also significantly higher in the posttest than in the pretest, $t(84)=4.20, p<.001$, Cohen's $d=.46$. This improvement was not observed in the control condition, $t(78)=.46, p=.64$, Cohen’s $d=.06$. 


\subsubsection{Parent specific self-efficacy}

As shown in Table 2, parents in both conditions were not significantly different in their specific self-efficacy in helping their children to be better readers in the pretest, $t(166)=1.5, p=.14$, Cohen's $d=.24$. In the posttest, however, the parents in the experimental condition reported significantly higher specific self-efficacy than the parents in the control condition, $t(162)=4.89, p<.001$, Cohen's $d=.76$. Their specific self-efficacy was also significantly higher in the posttest than in the pretest, $t(84)=7.98, p<.001$, Cohen's $d=.93$. In contrast, the parents in the control condition did not report such an increase from the pretest to the posttest, $t(78)=.41, p$ $=.68$, Cohen’s $d=.05$.

\subsubsection{Parent general self-efficacy}

As shown in Table 2, parents in both conditions were not significantly different in their general self-efficacy in helping their children to be better learners in the pretest, $t(166)=.70, p=.48$, Cohen's $d=.11$. In the posttest, however, the parents in the experimental condition reported significantly higher general self-efficacy than the parents in the control condition, $t(162)=3.60, p<.001$, Cohen's $d=.56$. Their general self-efficacy was also significantly higher in the posttest than in the pretest, $t(84)=5.16, p<.001$, Cohen's $d=.58$. In contrast, the parents in the control condition did not report such an increase from the pretest to the posttest, $t(78)=1.34$, $p=.19$, Cohen's $d=.11$.

\subsection{Mediation effects of parental changes}

The child outcomes may be directly driven by the program or through the changes of parenting behaviors. To test these two possible mechanisms, a series of mediation analyses were performed to check whether the changes in parenting measures could explain the program effects on the child outcomes. For each of the child outcomes, there were three mediation analyses. These three analyses tested the 
mediation effects of the changes in parent-child relationship, the changes in parent specific self-efficacy, and the changes in parent general self-efficacy, respectively. The bootstrapping method suggested by Preacher and Hayes (2004) was used to test the mediation. In the analyses, the independent variable was the condition. Control condition was coded as 1 and experimental condition was coded as 2 . The mediators were the difference scores between the pre and post parenting measures. The dependent variables were the difference scores between the pre and post measures of child outcomes. Table 3 reports the mean of the mediation effects estimated from 3,000 bootstrap resamples for each of the analyses. It was found that none of the parental changes mediated the program effects on children's word recognition and reading fluency. However, all the parental changes mediated the program effects on parents' perceived competence and motivation of children in reading. All the $p$ values were lower than .01 .

\subsection{Interaction between family income and condition}

Table 4 presents the estimated marginal means of all the posttest measures by family income and condition adjusted for the pretest measures. To investigate whether the program had differential effects on participants with different levels of family income, the interaction effect between family income and condition was examined with a series of two-way ANCOVA on the posttest measures, with the pretest measures as covariate. As shown in Table 4, none of the analyses indicated an interaction effect between family income and condition on the posttest measures. Most of the variables had a pattern similar to that of reading fluency as shown in Figure 2. The two lines indicating different family income levels were parallel. The program did not have differential effects on participants with different family income levels. Families with high and low income both benefited from the program alike. 


\section{Discussion}

\subsection{Positive effects on children}

Consistent with the hypotheses about the outcomes for children, although all the preschoolers made improvements as they were attending school, preschoolers in the experimental condition made more progress than their counterparts in the control condition. At the beginning of the program, there was no difference between the two groups in reading performance and motivation. However, the preschoolers in the experimental condition were able to recognize more words and read more fluently at the end of the program. These findings are consonant with those of Chow and McBride-Chang (2003) that early parental involvement has strong effects on children's literacy development in Chinese, a language that is not easy to master in reading and writing.

Compared to the study of Chow and McBride-Chang (2003), the present study goes one step further to show that the positive impact of early parental involvement is not only felt on emergent literacy skills but also on motivation. The parents in the experimental condition perceived that their children had more motivation to read at the end of the program than did their counterparts in the control condition. From a motivational standpoint, Baker (2003) criticized Topping's model of paired reading for excluding discussion between parents and children of the literal story content. By adding this kind of discussion to Topping's model, the present study shows that this modified paired reading approach could enhance children's motivation. As motivation is a central ingredient of reading success (Baker, Mackler, Sonnenschein, \& Serpell, 2001), this finding is very encouraging.

\subsection{Positive effects on parenting}

Another encouraging finding of the program is related to the changes in the parenting variables. During the seven-week program, the parents received 12 
individual sessions of supervised practice with their own child and participated in two small group review sessions. As they were coached intensively in paired reading by the teachers of their children, it was not a surprise that at the end of the program they had higher self-efficacy in helping their children to be better readers. Nevertheless, the increase in self-efficacy was not only restricted to helping their children to read, but was generalized to helping their children to be better learners. The program had empowered the parents in their parenting skills and abilities. They were more confident in using praise and encouragement in a timely manner and do so readily to reinforce their children's learning in general.

It is noteworthy that the program also enhanced the parent-child relationship. One may argue that it was not the program but the fact that the parents spent more time with their children that led the parents to rate their relationship better at the post test. This alternative explanation was unlikely because quality instead of quantity matters more in parent-child interaction, particularly when it involves helping children to learn. In fact parental involvement in children’s learning activities at home can be a source of parent-child conflict. Helping at home may increase parental emotional cost and tension between parents and children, particularly when the children cannot measure up to the parents' expectations (Levin et al., 1997). The association between parental involvement and academic achievement may not be a simple one. Patall, Cooper, and Robinson (2008) found that the association was influenced by numerous factors, including the involvement strategies parents used and the parents' own mentoring skills. In a survey of 709 parents, two-thirds of the parents reported some negative or inappropriate form of involvement (Cooper, Lindsay, \& Nye, 2000). Parental involvement with the wrong strategies or approaches may do more harm than good. In the present study, coaching by teachers helped parents 
acquire the appropriate strategies. The time for reading together was not a time for drilling but a time for enjoyable interaction. It is also a time for building children's success and stimulating children's interest and active participation in reading. As a result, parents in the experimental condition reported that they had a better relationship with their children at the end of the program.

\subsection{The mediating role of parental changes}

It was expected that parental changes mediated the program effects on child outcomes. This hypothesis was partly supported by the results. The mediating role of parental changes was found in parent perceived competence and motivation of the children. The parents in the experimental group reported more positive changes in parent-child relationship, specific self-efficacy, and general self-efficacy than their counterparts in the control group. In turn, these parental changes were associated with parents reporting higher competence and motivation of their children in reading. Nevertheless, the mediating role of parental changes was not found in objective tests of children's ability in word recognition and reading fluency. None of the mediating effects was significant statistically. These results may suggest that the program, rather than the parent behaviors, was driving the child outcomes in word recognition and reading fluency. The difference between the findings in the two sets of child outcomes may be related to the source of information. The measures of word recognition and reading fluency were from the objective tests administered by the teachers. In contrast, the measures of parent perceived competence and motivation were from the subjective report made by the parents. These measures shared the same source of variance with the mediators which were also from the subjective report made by the parents. As a result, the mediating effects of the parental changes reported by the 
parents were more obvious for the child outcomes which were also reported by the parents than those measured by other means.

\subsection{The moderating role of family income}

The present study did not find any interaction effect between family income and condition. Contrary to our expectation, the effectiveness of the program was not particularly strong for families with low income. Instead, the program was beneficial to all families regardless of their income levels. This result is inconsistent with Topping and Lindsay's (1991) finding that the children in the low SES category yielded bigger gains than the children in the high SES category. The inconsistency might be due to the fact that income instead of SES was measured in the present study. SES is a broader concept which includes not only family income but also education and occupation prestige. Nevertheless, the lack of moderating effect of family income may not be a disappointing result as it sends a positive message to educators that they should not assume that parents with high income know more than parents with low income. In fact, most parents need guidance and support in parental involvement (Baker, 2003). Specific advice on how to read with their children at home is helpful to most parents. No matter whether the parents and children come from families with high or low income level, they all benefit from good strategies and approaches in parental involvement.

\subsection{Contributions and Implications}

Many researchers (e.g., Erion, 2006; Powell-Smith, Stone, Shinn, \& Good, 2000) have pointed out that research on parent tutoring was often plagued by design problems. These problems include the use of quasi-experimental designs and the lack of data in treatment fidelity. In response to these problems, we conducted a randomized controlled trial and made a special effort to ensure that the parents 
mastered the required skills and strategies. With random assignment of participants to the experimental and control conditions, the present study was able to achieve high internal validity. With intensive support and close monitoring in the seven-week program, all the parents in the experimental condition were able to master at least $80 \%$ of the skills in our checklist. Guidance and support to parents are important not only for the sake of treatment fidelity but also for the sake of program effectiveness. As parents were the tutors of their children, parent education and empowerment were crucial for the program to be successful.

In fact, the most prominent implication of the present study concerns parent education and empowerment. The encouraging results indicate that schools are in a position to train parents in effective reading strategies and provide appropriate guidance and support. The ten preschools in the present study made a good demonstration of how to get parents involved in their children's literacy development. The instruction and assistance provided by the schools were not only helpful to families with low income; they were beneficial to families with high and low income levels alike. These results send a strong message to educators that they should make an effort to foster quality parental involvement. The positive impact is likely to be long-lasting because family-based intervention does not only affect children but also parents as it brings positive changes to parenting skills, parent-child relationship and routines of family life.

\subsection{Limitations and Future Direction}

Although the present study has made contributions to the research and practice in parental involvement, it has several limitations. First, it did not include any long-term measures after the program was completed. It is unknown whether the positive effects of the program are sustainable. To investigate the long-term effects of the paired 
reading program, it would be worthwhile to conduct a longitudinal study so as to follow up the impact on both children and parents. Second, although the present study was a field experiment with a randomized controlled trial, it could not exclude a possible placebo effect because the control group was a waitlist control group. To exclude the possibility of a placebo effect, future studies may have the parent-child dyads in the control group engaged in some other activity for a similar period of time. Third, the present study modified Topping's model by including discussion between parents and children on the literal story content. However, it did not investigate whether this addition could really produce better results than Topping's original approach. One meaningful direction for future studies in paired reading would be to compare these two models. Lastly, many measures in the present study were based on parent reports. Although parents are usually good informants of their own feelings and the behaviors of their children, the validity of the measures would be increased if these parent reports were supplemented by information from other sources. For example, child motivation in reading can be measured by how much time the children stayed in the reading corner in their classroom or how many books they check out from the school library.

\section{Conclusion}

To sum up, the results of the present study are encouraging. The paired reading program did not only have positive effects on children but also on parents. After the intervention, the preschoolers had better reading performance and were more motivated to read. The parents had higher self-efficacy in helping their children to be better readers and learners. They also reported a better relationship with their children. It is heartening to witness positive changes in parenting skills. This study sends a strong message to educators worldwide: It is worthwhile and rewarding to provide 
guidance and support to parents for their involvement in their children's literacy development. 


\section{Acknowledgement}

The authors wish to thank the voluntary coaches who spent many hours in training the teachers to be trainers. They are also grateful to the teachers who provided intensive coaching on paired reading to the parents in the program. 


\section{References}

Baker, L. (2003). The role of parents in motivating struggling readers. Reading and writing quarterly: Overcoming learning difficulties, 19, 87-106. doi: $10.1080 / 10573560308207$

Baker, L., Mackler, K., Sonnenschein, S., \& Serpell, R. (2001). Parents’ interactions with their first-grade children during storybook reading and relations with subsequent home reading activity and reading achievement. Journal of School Psychology, 39, 415-443. doi: 10.1016/S0022-4405(01)00082-6

Barnitz, J. (1982). Orthographies, bilingualism and learning to read English as a second language. The Reading Teacher, 35, 560-567.

Bus, A. G., van Ijzendoorn, M. H., \& Pellegrini, A. D. (1995). Joint book reading makes for success in learning to read: A meta-analysis on intergenerational transmission of literacy. Review of Educational Research, 65, 1-21. doi: $10.3102 / 00346543065001001$

Census and Statistics Department (2011). Quarterly report on general household survey: January to March 2011. Retrieved from http://www.statistics.gov.hk/publication/stat_report/labour/B10500012011Q Q01B0100.pdf

Chang, M., Park, B., Singh, K., \& Sung, Y. Y. (2009). Parental involvement, parenting behaviors, and children's cognitive development in low-income and minority families. Journal of Research in Childhood Education, 23, 309-324. doi: 10.1080/02568540909594663

Chow, B. W.-Y., \& McBride-Chang, C. (2003). Promoting language and literacy development through parent-child reading in Hong Kong preschoolers. Early Education and Development, 14, 233-248. doi: 
10.1207/s15566935eed1402_6

Coleman, J. S. (1988). Social capital in the creation of human capital. American Journal of Sociology, 94, 95-120. doi: 10.2307/2780243

Coleman, J. S. (1992). Some points on choice in education. Sociology of Education, 65, 260-262.

Cooper, H., Lindsay, J. J., \& Nye, B. (2000). Homework in the home: How student, family, and parenting-style differences relate to the homework process. Contemporary Educational Psychology, 25, 464-487. doi: 10.1006/ceps.1999.1036

Education Bureau (2006). Performance indicators (pre-primary institutions): Domain on children's development ( $2^{\text {nd }} \mathrm{ed}$.), Hong Kong: Author.

DeTemple, J. M. (2001). Parents and children reading books together. In D. K.

Dickinson \& P. O. Tabors (Eds.), Beginning literacy with language (pp. 31-51), Baltimore: Paul H. Brookes.

Epstein, J. (1987). Parent involvement: What research says to administrators. Education and Urban Society, 19, 119-136. doi: 10.1177/0013124587019002002

Erion, J. (2006). Parent tutoring: A meta-analysis. Education and Treatment of Children, 29, 79-106.

Evans, G. W. (2004). The environment of childhood poverty. American Psychologist, 59, 77-92. doi: 10.1037/0003-066X.59.2.77

Fitzgerald, J., Spiegel, D. L., \& Cunningham, J. W. (1991). The relationship between parental literacy level and perceptions of emergent literacy. Journal of Reading Behavior, 23, 191-192. doi: 10.1080/10862969109547736

Ginsburg, G. S., \& Bronstein, P. (1993). Family factors related to children’s 
intrinsic/extrinsic motivational orientation and academic performance. Child Development, 64, 1461-1474. doi: 10.1111/j.1467-8624.1993.tb02964.x

Goldenberg, C., Reese, L., \& Gallimore, R. (1992). Effects of literacy materials from school on Latino children's home experiences and early reading achievement. American Journal of Education, 100, 497-536.

Gonzalez-DeHass, A. R., Willems, P. P., \& Doan Holbein, M. F. (2005). Examining the relationship between parental involvement and student motivation. Educational Psychology Review, 17, 99-123. doi: $10.1007 / s 10648-005-3949-7$

Hanley, J. R., Tzeng, O., \& Huang, H.-S. (1999). Learning to read Chinese. In M. Harris \& G. Hatano (Eds.), Learning to read and write: A cross-linguistic perspective (pp.173-195). Cambridge, U.K.: Cambridge University Press.

Hewison, J. (1988). The long-term effectiveness of parental involvement in reading: A follow-up to the Haringey Reading Project. The British Journal of Educational Psychology, 58, 184-190. doi:

10.1111/j.2044-8279.1988.tb00891.x

Heymann, S. J., \& Earle, A. (2000). Low-income parents: How do working conditions affect their opportunity to help school-age children at risk? American Educational Research Journal, 37, 833-848. doi: $10.3102 / 00028312037004833$

Jiang, S., \& Li, B. (1985). A glimpse at reading instruction in China. Reading Teacher, $38,762-766$.

Kelly-Vance, L., \& Schreck, D. (2002). The impact of a collaborative family/school reading programme on student reading rate. Journal of Research in Reading, 25, 43-53. doi: 10.1111/1467-9817.00157 
Law, M., \& Kratochwill, T. R. (1993). Paired reading: An evaluation of a parent tutorial program. School Psychology International, 14, 119-147. doi: $10.1177 / 0143034393142003$

Lau, J. Y.-H., \& McBride-Chang, C. (2005). Home Literacy and Chinese Reading in Hong Kong Children. Early Education and Development, 16, 5-22. doi: 10.1207/s15566935eed1601_1

Levin, I., Levy-Shiff, R., Appelbaum-Peled, T., Katz, I., Komar, M., \& Meiran, N. (1997). Antecedents and consequences of maternal involvement in children’s homework: A longitudinal analysis. Journal of Applied Developmental Psychology, 18, 207-227. doi: 10.1016/S0193-3973(97)90036-8

Lonigan, C. J., \& Whitehurst, G. J. (1998). Relative efficacy of parent and teacher involvement in a shared reading intervention for preschool children from low-income backgrounds. Early Childhood Research Quarterly, 13, 263-290. doi: 10.1016/S0885-2006(99)80038-6

Li, H., \& Rao, N. (2000). Parental influences on Chinese literacy development: A comparison of preschoolers in Beijing, Hong Kong, and Singapore. International Journal of Behavioral Development, 24, 82-90. doi: $10.1080 / 016502500383502$

Li, H., \& Rao, N. (2005). Curricular and instructional influences on early literacy attainment: Evidence from Beijing, Hong Kong and Singapore. International Journal of Early Years Education, 13, 235-253. doi:

$10.1080 / 09669760500295870$

Marjoribanks, K. (1996). Family socialization and children's school outcomes: An investigation of a parenting model. Education Studies, 22, 3-11. doi: $10.1080 / 0305569960220101$ 
McBride-Chang, C., Lam, F., Lam. C., Doo, S., Wong, S. W. L., Chow, Y. Y. Y. (2008). Word recognition and cognitive profiles of Chinese pre-school children at risk for dyslexia through language delay or familial history of dyslexia. The Journal of Child Psychology and Psychiatry, 49, 211-218. doi:10.1111/j.1469-7610.2007.01837.x

McMackin, M. (1993). The parent’s role in literacy development. Childhood Education, 69, 142-145. doi: 10.1080/00094056.1993.10520914

Mol, S. E., Bus, A. G., De Jong, M. T., \& Smeets, D. J. H. (2008). Added value of dialogic parent-child book readings: A meta-analysis. Early Education and Development, 19, 7-26. doi: 10.1080/10409280701838603

Morgan, R. (1976) “Paired Reading” Tuition: A preliminary report on a technique for cases of reading deficit. Child: Care, Health and Development, 2, 13-28. doi: 10.1111/j.1365-2214.1976.tb00230.x

Overett, J., \& Donald, D. (1998). Paired reading: Effects of a parent involvement programme in a disadvantaged community in South Africa. British Journal of Educational Psychology, 68, 347-356. doi:

10.1111/j.2044-8279.1998.tb01296.x

Patall, E. A., Cooper, H., \& Robinson, J. C. (2008). Parent involvement in homework: A research synthesis. Review of Educational Research, 78, 1039-1101. doi: $10.3102 / 0034654308325185$

Powell-Smith, K. A., Stoner, G., Shinn, M. R., \& Good, R. H. (2000). Parent tutoring in reading using literature and curriculum materials: Impact on student reading achievement. School Psychology Review, 29, 5-27.

Preacher, K. J., \& Hayes, A. F. (2004).SPSS and SAS procedures for estimating indirect effects in simple mediation models. Behavior Research Methods, 
Instruments, \& Computers, 36,717-731. doi: 10.3758/BF03206553

Scarborough, H. S., \& Dobrich, W. (1994). On the efficacy of reading to preschoolers. Developmental Review, 14, 245-302. doi: 10.1006/drev.1994.1010

Sénéchal, M., \& Young, L. (2008). The effect of family literacy interventions on children's acquisition of reading from kindergarten to grade 3: A meta-analytic review. Review of Educational Research, 78, 880-907. doi: $10.3102 / 0034654308320319$

Scher, P. J. (1998). “Shared-reading intervention.” Early Childhood Research Quarterly, 13, 291-292. doi: 10.1016/S0885-2006(99)80039-8

Sonnenschein, S., Baker, L., Serpell, R., Scher, D., Truitt, V. G., \& Munsterman, K. (1997). Parental beliefs about ways to help children learn to read: The impact of an entertainment or a skills perspective. Early Child Development and Care, 127-128, 111-118. doi: 10.1080/0300443971270109

Tizard, J., Schofield, W., \& Hewison, J. (1982). Collaboration between teachers and parents in assisting children's reading. British Journal of Educational Psychology, 52, 1-15. doi: 10.1111/j.2044-8279.1982.tb02498.x

Tabors, P. O., Snow, C. E., \& Dickinson, D. K. (2001). Home and schools together: Supporting language and literacy development. In D. K., Dickinson \& P. O. Tabors (Eds.), Beginning literacy with language (pp. 313-334), Baltimore: Paul H. Brookes.

Topping, K. J. (1986). Effective service delivery: Training parents as reading tutors. School Psychology International, 7, 231-236. doi:10.1177/0143034386074007

Topping, K. J. (1987). Paired reading: A powerful technique for parent use. The Reading Teacher, 40, 608-614. 
Topping, K. J., \& Lindsay, G. A. (1991). Parental involvement in reading: The influence of socio-economic status and supportive home visiting. Children and Society, 5, 306-316. doi: 10.1111/j.1099-0860.1991.tb00496.x

van Steensel, R., McElvany, N., Kurvers, J., \& Herppich, S. (2011). How effective are family literacy programs? Results of a meta-analysis. Review of Educational Research, 81, 69-96. doi: 10.3102/0034654310388819

Weigel, D. J., Martin, S. S., \& Bennett, K. K. (2006). Mothers’ literacy beliefs: Connections with the home literacy environment and pre-school children’s literacy development. Journal of Early Childhood Literacy, 6, 191-211. doi: $10.1177 / 1468798406066444$

Weinberger, J. (1996). A longitudinal study of children’s early literacy experiences at home and later literacy development at home and school. Journal of Research in Reading, 19, 14-24. doi: 10.1111/j.1467-9817.1996.tb00083.x

White, K. R. (1982). The relation between socioeconomic status and academic achievement. Psychological Bulletin, 91, 461-481. doi: 10.1037/0033-2909.91.3.461

White, S. B., Reynolds, P. D., Thomas, M. M., \& Gitzlaff, N. J. (1993). Socioeconomic status and achievement revised. Urban Education, 28, 328-343. doi:10.1177/0042085993028003007

Whitehurst, G. J., \& Lonigan, C. J. (1998). Child development and emergent literacy. Child Development, 69, 848-872. doi: 10.1111/j.1467-8624.1998.tb06247.x Whitehurst, G. J., Falco, F. L., Lonigan, C. J., Fischel, J. E., DeBaryshe, B. D., Valdez-Menchaca, M. C., \& Caulfield, M. (1988). Accelerating language development through picture book reading. Developmental Psychology, 24, 552-559. doi: 10.1037/0012-1649.24.4.552 
Table 1

The Means and Standard Deviations of the Child outcomes in Pretest and Posttest across Conditions

\begin{tabular}{lccccc}
\hline & \multicolumn{2}{c}{ Pretest } & & \multicolumn{2}{c}{ Posttest } \\
\cline { 2 - 3 } \cline { 5 - 6 } Measures & Experimental & Control & Experimental & Control \\
\hline \multirow{2}{*}{ Word recognition } & $32.64^{\mathrm{a}}$ & $26.98^{\mathrm{b}}$ & & $47.36^{\mathrm{a}, 1}$ & $35.13^{\mathrm{b}, 1}$ \\
& $(26.76)$ & $(24.08)$ & $(28.12)$ & $(27.15)$ \\
Reading fluency & $25.27^{\mathrm{c}}$ & $21.99^{\mathrm{d}}$ & & $33.00^{\mathrm{c}, 2}$ & $28.01^{\mathrm{d}, 2}$ \\
& $(14.91)$ & $(14.06)$ & $(16.76)$ & $(15.74)$ \\
Parent perceived competence & $4.65^{\mathrm{e}}$ & $4.52^{\mathrm{f}}$ & & $5.65^{\mathrm{e}, 3}$ & $4.74^{\mathrm{f}, 3}$ \\
& $(1.15)$ & $(1.14)$ & & $(.83)$ & $(1.16)$ \\
Parent perceived motivation & $5.25^{\mathrm{g}}$ & $5.12^{\mathrm{h}}$ & & $5.88^{\mathrm{g}, 4}$ & $5.34^{\mathrm{h}, 4}$ \\
& $(.93)$ & $(1.15)$ & $(.87)$ & $(1.11)$ \\
\hline
\end{tabular}

Note. Numbers in parentheses are standard deviations. Means sharing the same letter superscript are significantly different between pretest and posttest. Means sharing the same numeric superscript are significantly different across conditions. 


\section{Table 2}

The Means and Standard Deviations of the Parenting Measures in Pretest and Posttest across Conditions

\begin{tabular}{lccccc}
\hline & \multicolumn{2}{c}{ Pretest } & & \multicolumn{2}{c}{ Posttest } \\
\cline { 2 - 3 } \cline { 5 - 6 } Measures & Experimental & Control & & Experimental & Control \\
\hline Parent-child relationship & $5.63^{\mathrm{a}}$ & 5.64 & $5.95^{\mathrm{a}, 1}$ & $5.69^{1}$ \\
& $(.73)$ & $(.83)$ & & $(.65)$ & $(.86)$ \\
Parent specific self-efficacy & $5.00 \mathrm{~b}^{\mathrm{b}}$ & 5.23 & & $5.84^{\mathrm{b}, 2}$ & $5.18^{2}$ \\
& $(1.04)$ & $(.90)$ & & $(.74)$ & $(.99)$ \\
Parent general self-efficacy & $5.18^{\mathrm{c}}$ & 5.07 & $5.70^{\mathrm{c}, 3}$ & $5.18^{3}$ \\
& $(1.00)$ & $(1.02)$ & $(.79)$ & $(1.04)$ \\
\hline
\end{tabular}

Note. Numbers in parentheses are standard deviations. Means sharing the same letter superscript are significantly different between pretest and posttest. Means sharing the same numeric superscript are significantly different across conditions. 
Table 3

The Mediation Effects of Changes in Parenting Measures between Intervention and Changes in Child outcomes

\begin{tabular}{lll}
\hline Child outcomes & Mediator & Mediation effect \\
\hline Changes in word & Changes in parent-child relationship & -.22 \\
recognition & Changes in parent specific self-efficacy & -.14 \\
& Changes in parent general self-efficacy & -.35 \\
\hline \multirow{2}{*}{ Changes in reading } & Changes in parent-child relationship & .04 \\
fluency & Changes in parent specific self-efficacy & .29 \\
& Changes in parent general self-efficacy & .07 \\
\hline \multirow{2}{*}{ Changes in parent } & Changes in parent-child relationship & $.11^{* *}$ \\
perceived competence & Changes in parent specific self-efficacy & $.38^{* *}$ \\
& Changes in parent general self-efficacy & $.17^{* *}$ \\
\hline \multirow{2}{*}{ Changes in parent } & Changes in parent-child relationship & $.12^{* *}$ \\
perceived motivation & Changes in parent specific self-efficacy & $.28^{* *}$ \\
& Changes in parent general self-efficacy & $.15^{* *}$ \\
\hline
\end{tabular}

Note. ${ }^{* *} p<.01$. The mediation effects are the mean of unstandardized coefficients estimated from 3,000 bootstrap resamples. 
Table 4

Estimated Marginal Means of the Posttest Measures and the Interaction Effect between Family Income and Condition

\begin{tabular}{|c|c|c|c|c|c|c|c|c|}
\hline \multirow[b]{2}{*}{ Measures } & \multicolumn{2}{|c|}{ Experimental } & \multicolumn{2}{|c|}{ Control } & \multicolumn{4}{|c|}{ Interaction between Income and condition } \\
\hline & $\begin{array}{c}\text { Low } \\
\text { Income }\end{array}$ & $\begin{array}{c}\text { High } \\
\text { Income }\end{array}$ & $\begin{array}{c}\text { Low } \\
\text { Income }\end{array}$ & $\begin{array}{c}\text { High } \\
\text { Income }\end{array}$ & $F$ & $d f$ & $p$ value & Partial $\eta^{2}$ \\
\hline Word recognition & $\begin{array}{l}44.35 \\
(1.65)\end{array}$ & $\begin{array}{l}45.66 \\
(1.83)\end{array}$ & $\begin{array}{l}35.82 \\
(1.61)\end{array}$ & $\begin{array}{l}41.87 \\
(2.02)\end{array}$ & 1.77 & 1,186 & 0.19 & .01 \\
\hline Reading fluency & $\begin{array}{l}30.71 \\
(1.00)\end{array}$ & $\begin{array}{l}32.54 \\
(1.11)\end{array}$ & $\begin{array}{l}29.10 \\
(0.97)\end{array}$ & $\begin{array}{l}31.09 \\
(1.22)\end{array}$ & 0.01 & 1,186 & 0.94 & 0 \\
\hline Parent perceived competence & $\begin{array}{c}5.69 \\
(0.11)\end{array}$ & $\begin{array}{c}5.53 \\
(0.13)\end{array}$ & $\begin{array}{c}4.77 \\
(0.11)\end{array}$ & $\begin{array}{c}4.76 \\
(0.15\end{array}$ & 0.33 & 1,178 & 0.47 & 0 \\
\hline Parent perceived motivation & $\begin{array}{c}5.98 \\
(0.10)\end{array}$ & $\begin{array}{c}5.67 \\
(0.13)\end{array}$ & $\begin{array}{c}5.48 \\
(0.11)\end{array}$ & $\begin{array}{c}5.18 \\
(0.14)\end{array}$ & 0.00 & 1,178 & 0.98 & 0 \\
\hline Parent-child relationship & $\begin{array}{c}5.98 \\
(0.89)\end{array}$ & $\begin{array}{c}5.95 \\
(0.11)\end{array}$ & $\begin{array}{c}5.72 \\
(0.09)\end{array}$ & $\begin{array}{c}5.59 \\
(0.12)\end{array}$ & 0.21 & 1,159 & 0.65 & 0 \\
\hline Parent specific self-efficacy & $\begin{array}{c}5.90 \\
(0.10)\end{array}$ & $\begin{array}{c}5.89 \\
(0.13)\end{array}$ & $\begin{array}{c}5.14 \\
(0.10)\end{array}$ & $\begin{array}{l}5.09 \\
(0.14)\end{array}$ & 0.02 & 1,159 & 0.88 & 0 \\
\hline Parent general self-efficacy & $\begin{array}{c}5.67 \\
(0.13)\end{array}$ & $\begin{array}{c}5.67 \\
(0.13)\end{array}$ & $\begin{array}{c}5.23 \\
(0.10)\end{array}$ & $\begin{array}{c}5.15 \\
(0.14)\end{array}$ & 0.11 & 1,159 & 0.74 & 0 \\
\hline
\end{tabular}

Note. The means have been adjusted for the pretest measures. Numbers in the parentheses are standard errors. 


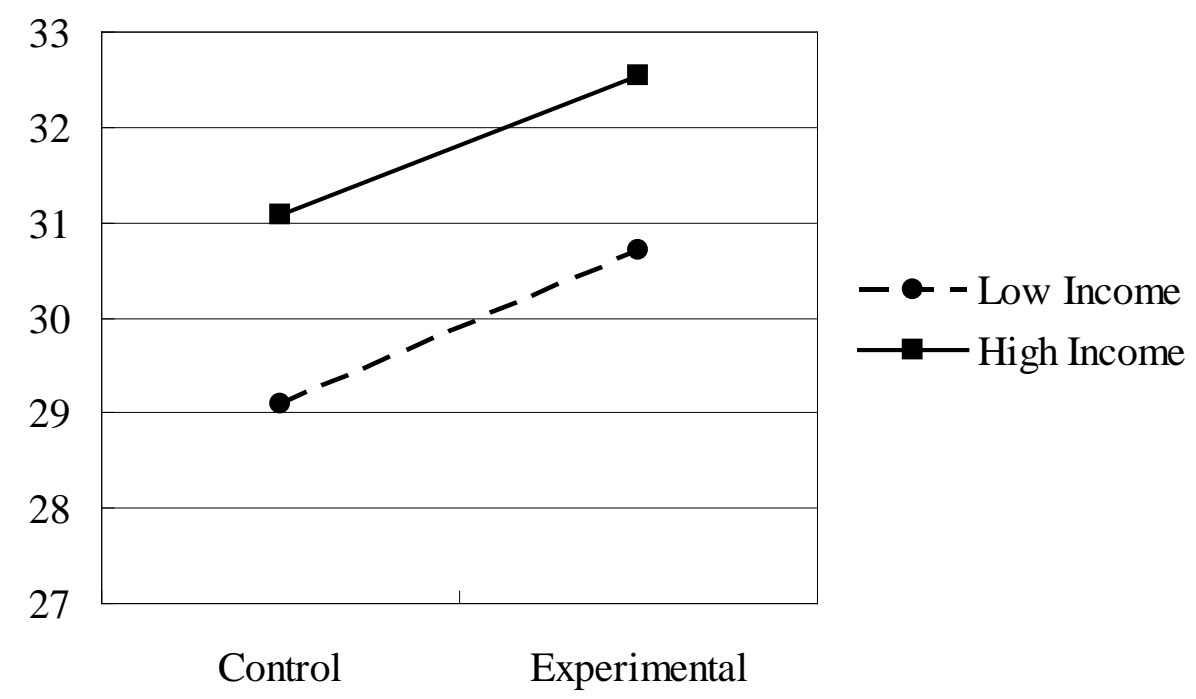

Figure 1. Estimated marginal means of the posttest reading fluency by condition and family income level. 